\title{
Body experience during post-acute rehabilitation in individuals after a traumatic spinal cord injury: a qualitative interview-based pilot study
}

\author{
Katharina Buchtler $\mathbb{D}^{1,2} \cdot$ Valerie Carrard $\mathbb{1}^{3,4} \cdot$ Hermine Jochum ${ }^{5} \cdot$ Katharina Ledermann ${ }^{2,6} \cdot$ Peter Lude ${ }^{3,6,7} \cdot$ \\ Anke Scheel-Sailer $\mathbb{D}^{1,4}$
}

Received: 16 May 2020 / Revised: 26 December 2020 / Accepted: 26 December 2020

(c) The Author(s), under exclusive licence to International Spinal Cord Society 2021

\begin{abstract}
Study design Qualitative interview-based pilot study.

Objectives A traumatic spinal cord injury (TSCI) profoundly disrupts the way individuals experience their body. Awareness of one's body is an important element in the psychological adjustment process after TSCI. This pilot study aimed to explore the body experience of individuals during post-acute rehabilitation following TSCI.

Setting Specialized acute care and rehabilitation center in Switzerland.

Methods Eight semi-structured face-to-face interviews were conducted with patients in the post-acute phase of their TSCI. Body experience was explored in relation to perceptive, cognitive, emotional, and behavioral aspects. The interviews were transcribed verbatim, and a structured content analysis was performed according to the Mayring method.

Results The individuals verbalized body experience in all explored aspects. The two participants with tetraplegia described high body-related awareness, including dependence on other persons or aids, whereas individuals with paraplegia focused on their ability to regain activity and perceived autonomy, which was sustained by increasing injury- and self-related comprehension. They expressed uncertainty in their understanding of their paralyzed body while also verbalizing to see a continuity in their identity pre and post TSCI. Their emotions varied from anxiety and anger to hope and optimism. The interviewees confirmed that the growing ability to describe perceptions related to their body increased their active participation in the rehabilitation process and stimulated hope for the future.

Conclusions Exploration of individual body experience after a recent TSCI can strengthen patients' body awareness, communication and engagement in rehabilitation and help the interprofessional rehabilitation team individualize the rehabilitation process.
\end{abstract}

Anke Scheel-Sailer

anke.scheel-sailer@paraplegie.ch

Swiss Paraplegic Centre (SPC), Nottwil, Switzerland

2 Department of Clinical and Health Psychology, University of Fribourg, Fribourg, Switzerland

3 Swiss Paraplegic Research, Nottwil, Switzerland

4 Department of Health Sciences and Medicine, University of Lucerne, Lucerne, Switzerland

5 Private, former, University Hospital Basel, Basel, Switzerland

6 Department of Consultation-liaison Psychiatry and Psychosomatics, University Hospital Zurich, Zurich, Switzerland

7 School of Applied Psychology, Zurich University of Applied Sciences (ZHAW), Zurich, Switzerland

\section{Introduction}

Spinal cord injury (SCI) leads to sudden impairment of sensation, motor function, and autonomic dysregulation below the lesion level [1]. The lesion and its effects lead to significant changes in body perception and destabilize an individual's understanding of the self [2]. The goal of acute care and rehabilitation after SCI is to achieve the best possible physical health and functioning, in accordance with the level and severity of the injury [3], and to maximize the individual's adjustment to the changed life conditions $[4,5]$.

The psychological adjustment process is influenced by early mental states during post-acute rehabilitation [6]. An individual's emotions are often overlooked due to the more evident physical impact of the disability [7]. However, depression occurs in up to $20-30 \%$ of individuals during 
early SCI rehabilitation $[3,5,8]$. Therefore, individuals need to be supported from a biopsychosocial perspective which stresses the importance of injury-related emotional and mental consequences, in order to facilitate decisionmaking, personal growth, and successful adjustment to the altered life conditions [7, 9].

The relation between the physical and psychological adjustment process is sustained by the concept of embodiment [10]. Mental processes (awareness, cognitive evaluations, attitudes, and emotions) are interrelated with physical body states (motor behavior, physical perceptions) and can only be understood in relation to the body in the context of a specific situation (e.g., frustration after a chair-to-bedtransfer failed can inhibit motivation, and muscle tone) $[10,11]$. Individual embodiment can be explored by considering various aspects of body experience. One of the existing concepts of body experience, described by Joraschky et al. [12] includes the notion of body-related perceptive (sensory information, body orientation), cognitive (body attitude, body knowledge, and body fantasies, ego), emotional (body awareness, satisfaction), and behavioral aspects (motor behavior, mimic, gesture, and posture) as well as their integration into a complex body representation.

The aim of this pilot study is to explore individuals' body experience during the post-acute phase after a recent traumatic spinal cord injury (TSCI) using interview questions addressing the perceptive, cognitive, emotional, and behavioral aspects of body experience.

\section{Methods}

\section{Design}

This was a qualitative pilot study in the field of TSCI and body experience during post-acute inpatient rehabilitation. The study received ethical approval from the Ethics Committee of Northwest and Central Switzerland (EKNZ 201801623). We used the "Consolidated criteria for reporting qualitative research" (COREQ) for reporting the study [13] (Appendix).

\section{Sampling and recruitment of participants}

Between September and November 2018, eight participants were recruited from all inpatients undergoing post-acute rehabilitation for SCI at a specialized acute care and rehabilitation center in Switzerland by screening the internal patient database (KB) according to the inclusion criteria of the study: complete TSCI, at least 3 months after injury and not less than 1 month before discharge, aged between 18 and 65 years, fluent in German or English, absence of serious cognitive and/or communication impairment, and absence of psychiatric diagnoses influencing the rehabilitation process.

Individuals meeting the inclusion criteria were presented (KB) to the respective rehabilitation team. The team decided whether to involve the patients in the study or not. Asking individuals about a change in their body experience after a recent TSCI can place an emotional burden on them. Thus, we decided to interview only individuals who demonstrated emotional stability. Then, the project leader (AS) asked the selected eight persons (face to face) about their willingness to participate. All individuals who agreed to participate, received (AS) the study information, and provided informed written consent. Afterwards, an appointment for the interview between the interviewer (KB) and the participant was scheduled. The interviewer (KB) had no therapeutic relation with the participants. Participants were informed that the interviews were being conducted as part of the interviewer's master thesis in the context of an internship in the area of psychological counseling in the rehabilitation center. The participants did not receive any compensation for their participation.

\section{Participants}

At the time of the interviews, all participants were between the third and fifth month of post-acute rehabilitation after TSCI. Two of the eight participants were women, and the overall mean age was 33.25 years, ranging from 19 to 62 years. Two participants had complete tetraplegia, and six had complete paraplegia. Half of the individuals' TSCIs were sports related, and the other half were due to a fall or traffic crash (Table 1).

\section{Development of the interview guide and data collection}

The semi-structured interviews were inspired by the aspects of body experience described by Joraschky et al. [12] and by different body experience and body image questionnaires [14-18]. It was developed in collaboration with an experienced psychologist (HJ) specialized in body-experience research in SCI and adjusted with an experienced rehabilitation physician (AS) (Table 2). The interviews were semi-structured in order to identify unexpected contents. Five pilot interviews were rehearsed with two individuals affected by a complete TSCI and three able-bodied individuals (one medical doctor and two students) to improve the interviewer's (KB) technique. Eight individual in-person interviews were then conducted and audio recorded for transcription purposes with a mobile device in a private office at the rehabilitation clinic. The average length of the interviews was $46 \mathrm{~min}$. Interviews were introduced using a short body scan based 
Table 1 Participants characteristics.

\begin{tabular}{lllll}
\hline Participant & Sex & Age & Diagnosis and AIS classification & Cause of lesion \\
\hline 1 & M & 40 & Paraplegia sub Th5, AIS A & Fall \\
2 & M & 62 & Tetraplegia sub C2, AIS A & Sport and leisure \\
3 & M & 22 & Paraplegia sub Th5, AIS A & Traffic crash \\
4 & W & 25 & Tetraplegia sub C6, AIS A & Sport and leisure \\
5 & M & 33 & Paraplegia sub Th11, AIS A & Traffic crash \\
6 & M & 19 & Paraplegia sub Th11, AIS A & Work-related fall \\
7 & M & 36 & Paraplegia sub Th12, AIS A & Sport and leisure \\
8 & W & 29 & Paraplegia sub Th8, AIS A & Sport and leisure \\
\hline
\end{tabular}

Table 2 Sample questions for the semi-structured interview.

\begin{tabular}{|c|c|}
\hline Physical body experience & $\begin{array}{l}\text { If you want, you can close your eyes to better concentrate on your body experience. } \\
\text { How do you perceive your body in this moment? What do you feel in your body? } \\
\text { Where exactly do you perceive something in your body? } \\
\text { How does that feel? }\end{array}$ \\
\hline Cognitive body experience & $\begin{array}{l}\text { I suppose that everybody has a specific image of him or herself, which can also be influenced by phantasies or } \\
\text { different attitudes. } \\
\text { How would you describe yourself as a person? } \\
\text { Do you have an idea how a man/a woman has to be? } \\
\text { Which expectancies do you have toward yourself concerning your daily life? } \\
\text { Did you know a person with a disability before you had the injury? } \\
\text { If yes, how was your contact with that person? } \\
\text { Did your attitudes towards disability change since the Spinal Cord Lesion? } \\
\text { Which importance have the parts of your body you cannot feel or move anymore for you? }\end{array}$ \\
\hline Emotional body experience & $\begin{array}{l}\text { How do you feel in your body? } \\
\text { Where do you feel well/bad in your body? } \\
\text { If you look at you or if you see yourself in a mirror, how do you react to yourself? } \\
\text { Do you have different emotions towards yourself in different situations or moments? } \\
\text { Did you perceive a change concerning these feelings since the beginning of the rehabilitation? }\end{array}$ \\
\hline Behavioral body experience & $\begin{array}{l}\text { In which way do you feel your body needs or desires? } \\
\text { How do you express yourself and your needs? } \\
\text { Did your way to communicate your needs change since the beginning of the SCI? } \\
\text { Are there situations or contacts where you have more difficulty to express yourself? } \\
\text { Do you experience yourself differently when you are e.g., in the wheel chair, in movement or laying in the bed? }\end{array}$ \\
\hline Ending questions & $\begin{array}{l}\text { Which recommendation would you give a recently injured patient concerning how to learn to handle the disability? } \\
\text { With which topics did you deal with and how this helped you? What did you learn about yourself, what you did } \\
\text { not knew before the injury? }\end{array}$ \\
\hline
\end{tabular}

on mindfulness techniques, e.g., "If you want, you can close your eyes to better concentrate on your body experience. How do you perceive your body in this moment?" [19].

\section{Data analysis}

The audio recordings were transcribed verbatim by one researcher (KB), according to the guidelines of Dresing, Pehl, and Spengler [20]. The participants did not check the transcriptions. Based on the structured content analysis of Mayring [21], transcripts were analyzed by one researcher (KB) in the original language by categorizing quotes inductively with the support of MAXQDA $12^{\odot}$ (VERBI Gmbh, version 2018) to identify aspects relevant to the research question. Quotes from every interview were then paraphrased and summarized to codes (e.g., "Body feels permanently tired," "Constant pressure and feeling of heaviness," "Paralyzed body parts do sometimes not feel like being part of the body," "Attempts to move something are exhausting"). Emerging codes were further summarized into categories (e.g., "Physical perceptions in the healthy body parts"), which were then compared between the eight transcripts and subsequently summarized and regrouped again. The codes of two randomly selected interviews were cross-checked by another researcher (AS), and a third researcher $(\mathrm{HJ})$ reviewed all the selected codes and identified categories. The categories were then discussed (KB, HJ, and AS) to include different perspectives and resolve uncertainties. 
Table 3 Quotes about physical perception.

\begin{tabular}{|c|c|}
\hline 1 & "I have no [sensitivity], I do not feel anything." (man (m), paraplegia (p)) \\
\hline 2 & $\begin{array}{l}\text { "I also have more pain and spasticity toward the evening. In the morning [I feel] normally really good } \\
\text { and then it begins slowly to decrease towards the evening. So the more I sit and the more I am up and } \\
\text { doing things." (m, p) }\end{array}$ \\
\hline 3 & $\begin{array}{l}\text { "[...] constant tingling in the legs and more or less severe pain, neuralgic pain in the feet }[\ldots] \text { which is } \\
\text { relatively constant. And with the time it feels painful, so it is like an overstimulation }[\ldots] . \text { " (woman } \\
\text { (w), tetraplegia (t)) }\end{array}$ \\
\hline 4 & $\begin{array}{l}\text { "In the whole part which I mostly cannot feel, I perceive kind of a warm tingling. Now, for example, a } \\
\text { tingling in the fingers, somewhere underneath the knees, in the arms and that tells me "Now you are } \\
\text { relaxed again'." (m, t) }\end{array}$ \\
\hline 5 & $\begin{array}{l}\text { "There is everywhere the tingling. [...] I would like to contract the muscle and it may not work but it is } \\
\text { like, the sensation is still there that something inside is moving. It is like having a lot of fireflies }[\ldots] \text { in } \\
\text { your legs which are always going around and in the moment you would press [the legs] together they } \\
\text { go all to one point." (w, t) }\end{array}$ \\
\hline 6 & $\begin{array}{l}\text { "A normal feeling of [my arms] just being part of me. I cannot say that I have a special feeling in my } \\
\text { arms or I do not know how to verbalize that." }(w, t)\end{array}$ \\
\hline 7 & $\begin{array}{l}\text { "Nothing, totally normal. I feel, in the arms and the upper torso it does not matter which time of the } \\
\text { day it is. It is always more or less the same." (m, p) }\end{array}$ \\
\hline 8 & "Especially in the areas which I do still feel I am a lot more sensitive." (m, p) \\
\hline 9 & $\begin{array}{l}\text { "In the upper torso I do not perceive anything. Simply, when the pain comes, I am tensed, }[\ldots] \text { really } \\
\text { tensed." }(\mathrm{m}, \mathrm{p})\end{array}$ \\
\hline 10 & "Soothed. Like relaxed $[\ldots]$ in my shoulders and like the torso area. $[\ldots]$ Easy day. " (m, p) \\
\hline
\end{tabular}

Following the principles of the COREQ criteria, we checked for saturation of the major categories by comparing emerging aspects between the first six and the last two interviews.

\section{Results}

The analysis identified the following six categories, which were also confirmed during the saturation check on the last two interviews.

\section{Category 1: Physical perception}

(Table 3) In the participants' description, physical perception of the body included the perception of sensory information on the body surface and internal body signals.

In the paralyzed parts of the body, the physical perception was described as dominated by the absence of sensitivity (Q1), the presence of spasticity, neuropathic pain (Q2), and constant or intermittent tingling, which was related to pain $(\mathrm{Q} 3)$, relaxation $(\mathrm{Q} 4)$, or the sensation that something was still active in the paralyzed body parts (Q5). In the body parts not affected by the lesion, many individuals expressed difficulty in verbalizing perceptions (Q6), ranging from constantly normal feelings (Q7), higher sensitivity than before the injury (Q8), no feeling, or feelings related to pain $(\mathrm{Q} 9)$ or relaxation $(\mathrm{Q} 10)$.

\section{Category 2: Perception of the self}

(Table 4) "Perception of the self" described the consciousness of a continuity of individuals' identity pre and post TSCI, although the body and person changed due to the consequences of the injury and individual adjustment.

The participants only perceived small changes in their physical appearance following the TSCI and felt they were still the same person as before the injury (Q11). All participants described their paralyzed body as being part of their body (Q12). However, many expressed incomprehension of the dysfunction in their paralyzed body parts (Q13) and difficulty in accepting them from a long-term perspective, given that they no longer fulfill their original function (Q14). People with paraplegia did not describe themselves as disabled (Q15); their description of body experience focused on the remaining abilities to be active, which were greater than previously imagined (Q16). They verbalized the necessity to get used to this unfamiliar body condition (Q17). In contrast, individuals with tetraplegia described their body experience as dominated by the experience of total dependence, which was an emotional burden for them (Q18). Some participants described the lack of feeling movement and activation in their whole body as an important concern (Q19). Individuals with tetraplegia reported that they are almost always focused on their body (Q20) and that they perceive themselves as more disabled than people with paraplegia, for example, with regard to their body movements (Q21). 
Table 4 Quotes about perception of the self.

11

12

13

14

15

16

17

18

19

20

21
"I think when I see myself on the photos that I am still the same as before. And, what reassures me the most, is that almost all visitors say that they see the same [person] as before. [...] [My body] still looks [...] quite similar to before the injury. Only the muscles have become a bit smaller but otherwise quite similar." (m, t)

"Because [my legs are still] part of me. [They are] still not gone. [...] On the one hand, I still love this part of my body. It belongs to me." (w, t)

"Oh, in a way [this part] belongs to me. How can it be that I really do not feel it?" (w, t)

"[...] so that I can see the legs again as legs I really have to relearn to walk or at least be able to do the stairs or something like that." (m, p)

"I am not able to say that I am disabled. It is something what is missing now [...]."(m, p)

"Still a lot is possible as a paralyzed person. Before [the injury] I always thought that being paralyzed is the worst [thing] that can happen to you and that you would not be able anymore to do anything. Really bad. But it is not at all like that. For sure, there are more severe cases, if you are a high tetra or something like that, then it is not funny anymore." (m, p)

"It is strange but it is a matter of getting used to it." (m, p)

"[... I am] completely dependent. I think the main topic is [...] total dependency. (experiences spasticity) I interpret [the occurrence of spasticity] as an emotional spasticity, because I told that I am only able to move the head and half of the upper torso and so I am emotionally affected. Because [I am] paralyzed, quasi $80 \%$ of my body." ( $\mathrm{m}, \mathrm{t})$

"I would for example absolutely love to be fully tired again, fully tired legs from running [...], from moving. [...] I am permanently tired because I am never really activated. My circulation is not activated anymore, my whole body is not activated anymore. [...] My shoulders, my arms [are] tired but my body as a whole [is] occasionally or hardly ever [activated]. [...] And so I feel often like unsatisfied." (w, t)

"Due to the lesion, [I have] a quite smaller [and really concentrated] focus on some things [...]. The whole day [I] am not doing anything else than caring about my body and the lesion. Hence, [I have] an incredible awareness or recognition what happens with [my] body." ( $\mathrm{m}, \mathrm{t})$

"She has been paraplegic and I think that they do not look as disabled as a tetra. I see that on myself when I move and take something with my hand. You [...] appear differently." (w, t)

\section{Category 3: General attitudes toward disability}

(Table 5) The experience of the self in a body with a disability influenced individuals' knowledge and changed their attitudes to other persons with a disability, as well as thoughts about the self.

Individuals characterized their attitudes prior to the injury as unawareness of the invisible impact of disability (Q22) and noted that, due to their own injury, they had become aware of the daily obstacles a person with paraplegia or tetraplegia must face (Q23). Some of them reported that their previous assumption-that physical impairment is linked to mental impairment-had changed due to their firsthand experience, and having a disability does not necessarily mean having a mental impairment (Q24). The participants expressed their recognition that each person is different, although they may share injuryrelated characteristics (Q25).

\section{Category 4: Body-related emotions}

(Table 6) Exploring body experience, different emotions emerged and were related to topics of autonomy and acceptance.
All individuals verbalized the simultaneous existence of anxiety and hope concerning their current and future body state (Q26). Frustration and sadness also occurred regarding their absence of sensitivity (Q27) and inability to control their paralyzed body parts voluntarily when they moved involuntarily due to spasticity (Q28). Some even verbalized anger at themselves due to the obstacle of paralysis (Q29). Well-being was related to better health condition (Q30), relaxation (Q31), improvement, or increased autonomy, such as improved bladder and bowel management (Q32). One participant described refusing to accept the paralyzed body by not caring for it, except when specific care was required (Q33), while others tried to reestablish a connection with their paralyzed body by appreciating and taking care of it (Q34).

\section{Category 5: Body-related communication}

(Table 7) Finding words for body states and experiences within their own body increased body-related understanding and improved communication.

The participants indicated that body awareness and communication of personal experiences were important to make outsiders understand their situation and behavior, 
Table 5 Quotes about general attitudes toward disability.

22

24

25

Table 6 Quotes about body-related emotions.
"[I thought that it] may not be easy for such a person. Especially para, because we never thought of tetra and I always said [... that] one cannot imagine how it would be [with a paralysis], if you do not experience it by yourself." ( $\mathrm{m}, \mathrm{t}$ )

"When you are yourself in a situation like that you notice how much is part of that [and] everything that is no longer possible, everything that is changing, how everything changes. [...]" (w, t)

"I have always put them $[\ldots]$ the sort of same category as brain injuries." (m, p)

"But a paralyzed person is not a paralyzed person." (m, p)

26 "[...] the anxiety that it will remain like that is allowed to be there. Just like the hope needs to stay, the anxiety also is allowed to stay." (w, t)

27 "I mean unfortunately there are no feelings. [...] Of course I feel bad. Compared to the before it is a bad situation." (m, p)

28 "I am often sad when I see my legs or my feet and spasticity arises. When I want to lift myself and see that they are able to move, but I am not, in a way. And that makes me sad [...]." (w, t)

29 "I am just angry about my body because I cannot do it. [...] not many people, not many, I have goals, not many things stop me from doing things. Now I have got something that is a brick wall I cannot go through." (m, p)

30 "I feel principally good. According to the circumstances, according to: 'I may be paralyzed, but I am actually doing really well'." (m, t)

31 "Feels good, you know. Rather be relaxed than stressed. It makes life a lot easier when you are just chilled out." (m, p)

32 "I am feeling well. Especially well because I have a regulated bowel movement since 2 or 3 weeks." (m, $t$ )

33 "Not so good, not so nice. In the shower, sure, [I] need to wash [the legs] and care for them, but when I am in bed, I throw them in any corner. [..] Legs are not really important [in that situation]." (m, p)

34 "I try to move every evening some parts a little bit and often stroke my legs. Trying to reestablish a connection and trying to treat my body really carefully and treating consciously also the part which I do not feel anymore." (w, t)

which increased the support they received (Q35) and helped relatives deal with the situation (Q36). Verbalizing personal needs and preferences made it possible to discuss situations and adjust the support to their individual needs (Q37). Nevertheless, participants expressed that asking for help with their self-perceived less important needs was more difficult than asking for assistance with obviously important needs (Q38).

\section{Category 6: Body-related thoughts about the future}

(Table 8) Talking about body experience, thoughts about future challenges with their body with a disability influenced individuals' motivation to be active and autonomous.

Individuals' body functions were constantly alternating between improvement and stagnation, resulting in insecurity about their future (Q39). Many participants verbalized worries concerning their ability to cope with upcoming situations in their lives (Q40). Most expressed a desire to return to the life they had before their injury, acknowledging that their present life was quite different from the previous one $(\mathrm{Q} 41)$. They described the importance of being physically active (Q42) and autonomous as they were prior to their injury (Q43), and they did not emphasize specific gender role-related expectations of themselves (Q44).

The participants reported acquiring SCI-related knowledge and adopting specific techniques in order to cope with their daily life and take care of their body (Q45). They said that an optimistic attitude (Q46) and hope (Q47) were essential for dealing with their new life. Allowing them to accept themselves and appreciate even small progress (Q48), they recognized the need to adapt their physical goals in light of their new reality (Q49). Their active participation in the rehabilitation process (Q50) led to a perceived sense of autonomy and less need for external assistance and help (Q51).

\section{Discussion}

The body-centered interview questions, integrating Joraschky's categories [12] and other concepts [14-16], stimulated the participants' body awareness and reflection on their individual physical and psychological adjustment process to TSCI-related changes.

The understanding of the body and the TSCI-related consequences to individual health- and future life perspectives dominated the body experience in individuals after TSCI. This understanding for both the individuals, and significant others and health professionals, can be increased through exploration and verbalization of physical, cognitive, emotional, and behavioral aspects of the body experience.

When we started the interviews with questions related to physical perception, the important topic of bowel and 
Table 7 Quotes about body-related communication.

35

36

38

Table 8 Quotes about body-related thoughts about the future. you do." (w, t)
"A big advance is certainly that my brain is fully [intact] and so I am aware of my body and also able to express it. Hence, I may get better support from the medical doctors, the therapists and from the entire environment. Therefore, I get a better awareness or notice a better awareness from my entire body. And I also look at [my body] and notice things [...]." (m, t

"I think communication is incredibly important. If you do not want to speak, do not say a lot, but explain to the people briefly, how it is. Because those who are close to you suffer at least as much as

"[...] I want some therapies to be maybe a little adapted or optimized and to discuss that together with me or I suggest, or reversed, the therapists suggest [something] with the [idea] to get ahead. [...] that I really express my needs because I have the impression that in this rehabilitation time it is actually necessary to express all needs. If they can be fulfilled or if they are understood is another question, but at least one can express and discuss them $[\ldots] . "(m, t)$

"There are situations which are more difficult [...]. The more it is to ask, the easier I do it. Concerning little things I experience more difficulty." (w, p)

\begin{tabular}{|c|c|}
\hline 39 & $\begin{array}{l}\text { "This is also something strange that always something changes and }[\ldots] \text { will change even more within } \\
\text { the passage of time. You never know how it will finally be." }(\mathrm{m}, \mathrm{p})\end{array}$ \\
\hline 40 & $\begin{array}{l}\text { "And there are moments which are more going in the direction that nothing goes ahead or what does } \\
\text { that mean for me within } 6 \text { or } 12 \text { or } 18 \text { month? How will I handle [the situation]? May I be still able to } \\
\text { consider [my situation] as positive as I do now?" }(\mathrm{m}, \mathrm{t})\end{array}$ \\
\hline 41 & $\begin{array}{l}\text { "I still want to continue the same way if possible, of course. We will see how life takes. Because we do } \\
\text { not know. There are many questions [...] that need to [be] answered. Because it is absolutely true that } \\
\text { life before and now is not the same." (m, p) }\end{array}$ \\
\hline 42 & "Before that accident I was a very active person and I was doing all [by myself]." (m, p) \\
\hline 43 & $\begin{array}{l}\text { "I have been autonomous in my job and all my life it has been important to me to do things } \\
\text { myself." (w, t) }\end{array}$ \\
\hline 44 & $\begin{array}{l}\text { "I think it depends on the individual and the own character, the appearance, how this is connected. For } \\
\text { me in the end it is totally irrelevant if [you are a] man or woman. You have to love yourself, you have } \\
\text { to be true to yourself, and find back to yourself." (w, t) }\end{array}$ \\
\hline 45 & $\begin{array}{l}\text { "I have learned a lot within the } 5 \text { months. About me and my body. About my perception, about the } \\
{[\ldots] \text { symptoms or about these injuries." }(\mathrm{m}, \mathrm{t})}\end{array}$ \\
\hline 46 & $\begin{array}{l}\text { "I am having rather a positive attitude that everything will be successful or will come well. I do not } \\
\text { necessarily see the worst case." }(\mathrm{m}, \mathrm{t})\end{array}$ \\
\hline 47 & $\begin{array}{l}\text { "Do not allow to deprive you of the hope. [...] Do not allow to take the room for hope. Do not be naive } \\
\text { but a little hope you have to maintain, always." }(w, t)\end{array}$ \\
\hline 48 & $\begin{array}{l}\text { "I have many expectations toward myself and I also achieve all. When I have something in mind, it } \\
\text { normally takes } 2 \text { or } 3 \text { weeks }[\ldots] \text {. I had a shower by myself, all these little things. You are not able to } \\
\text { do everything right from the start, but that is ok. }[\ldots] \text { " }(\mathrm{m}, \mathrm{p})\end{array}$ \\
\hline 49 & $\begin{array}{l}\text { "I guess for so long I was just wishing I could walk. But now, [I am just] wishing I can get bowel } \\
\text { control moved }[\ldots] . "(\mathrm{~m}, \mathrm{p})\end{array}$ \\
\hline 50 & $\begin{array}{l}\text { "[...] Not thinking about, participating here, the therapies and everything. Focalizing on that. One can } \\
\text { certainly also have a good life in a wheel chair." }(\mathrm{m}, \mathrm{p})\end{array}$ \\
\hline 51 & $\begin{array}{l}\text { "And it is also somehow about to show 'I am not as disabled like I have once been'. [...] I found } \\
\text { possibilities to be independent and to be a lesser or no burden to [others]. I think it also has a lot to do } \\
\text { with that." (w, t) }\end{array}$ \\
\hline
\end{tabular}

bladder management [22] was expressed. Exploring physical perception can help the patients to verbalize bladder and bowel issues, which might be difficult to talk about due to shame. This topic is associated with the perception of control, autonomy, self-esteem, satisfaction, and quality of life, as emphasized in the previous literature [5, 23-25]. For participants, it seemed to be easier to talk about bowel and bladder management and different sensations in their paralyzed body parts than to verbalize their perceptions of body parts not affected by the lesion. Our explanation for this is that body parts that feel "normal" or at least do not cause any pain or obstacles are less consciously perceived. Also, Bailey et al. emphasized that participants discussed negative body image experiences more easily [26]. For persons who do not feel all parts of their body, information coming from their sensitive body parts can help them to 
perceive and satisfy their general bodily needs (e.g., feeling a kind of tension in the arms when having a full bladder). Therefore, rehabilitation clinicians might help to explore the sensitive parts of the body and the individuals' strengths as well as the disabled parts of their body to increase understanding of the body functions and needs.

Exploring aspects of body-related cognition, participants verbalized the importance of increasing their knowledge of their body and body functions, as the understanding of their body and their person was destabilized. The awareness that their physical appearance had not drastically changed since the injury, helped individuals to see a continuity in their physical body and their identity pre and post TSCI. This is known to help a person develop more self-confidence [9]. Past research showed that the perception of a more or less stable physical appearance increased satisfaction with an individual's own body image [27]. Thus, increasing the understanding of the body can support acceptance of the body and the adjustment of the individuals' identity to bodily changes. This supports the notion that active engagement, education and knowledge transfer are important to foster self-exploration and selfreflection during rehabilitation $[28,29]$.

When asked about body-related emotional aspects, participants reported that an absence or decrease of pain increased satisfaction and well-being, which has also been reported in the literature [30]. Individuals expressed additional emotions, such as anxiety, anger, and insecurity, related to the difficulty in harmonizing personal goals with their functional abilities, as relevant aspects of their body experience [31]. The topic of hope emerged during the interviews based on the exploration of different aspects of body experience. Hope was an important feeling, which is recognized as a facilitator of adaptive coping strategies post-SCI [32-34] and has been linked to better adjustment [35]. Psychological adjustment after TSCI and well-being within the body and person are heterogeneous, influenced by individual physical, psychological, social, and environmental factors [36-40]. Participants highlighted their hopeful attitudes toward physical recovery and increasing autonomy, based on trust in their body and the perception of a continuity in their identity pre and post TSCI. Rehabilitation professionals can help individuals during the postacute phase after TSCI to withstand the emotional ambivalence between hope and anxiety or anger, and therefore, support the development of a healthier body image [21], acceptance of one's body, including related physical and psychological experiences [16, 36, 37].

Exploration of body-related behavior seemed to be difficult for the participants during the post-acute phase of rehabilitation, as they still perceived changes in their sensory perception, mobility, and functionality. Thus, they found it difficult to use and control their body and to verbalize how they use their body to express themselves. Their voice became a more important instrument than facial expressions, gestures, or posture. Expressing their body experience was crucial for increasing health professionals' and relatives' understanding and awareness of the situation of the participants. In particular, individuals with tetraplegia emphasized that open discussions facilitated handling their situation for everybody and contributed to their ability to receive adequate support [41]. Therefore, communication was important for expressing their physical body perception, thoughts, and emotions. Patient-centered communication can be improved by education and trainings for healthcare professionals to increase their ability and selfconfidence to ask individuals about their experiences, emotions and needs [42, 43]. Learning from the experience of others, e.g., peer support, can improve communication and relationships, support self-management and allow time and space for individuals with new SCI's to talk about important issues [44, 45].

An appreciative and interested attitude during interactions with patients can create an atmosphere of openness, awareness, warmth, and respect. Such a mindful atmosphere [19] leads to the feeling of safety, supports individuals' selfexpression, and is important for improving their adjustment process, participation in decision-making, and selfacceptance during rehabilitation [9]. Increasing awareness of the own body and different body states (by asking for perceptions and needs), gaining new experiences with the body (during activity and interactions) [10], assuming the responsibility to care for it, and learning to better communicate, can empower the individual with TSCI to assume the role of specialist of his or her body and person.

\section{Conclusion}

This pilot study provides in-depth insight into participants' body experience after TSCI, who share the experience of a lesion to the spinal cord but differ in their specific personal circumstances as well as in their cognitive and emotional perceptions of the situation. The exploration and verbalization of individuals' experiences and needs related to their paralyzed and non-paralyzed body parts, to their emotional ambivalence between the hope for recovery and the anxiety for future perspectives and changed possibilities to be autonomous, emerged as basis for the understanding of their body and further physical and psychological adjustment processes after TSCI.

Rehabilitation professionals play a crucial role in stimulating and supporting behavioral, emotional, and verbal reactions to the injury, as they are present during individuals' first experiences with their body after SCI. Showing an interest in different aspects of patients' 
experiences during the adjustment process, analyzing these aspects together, and encouraging individuals to increase body awareness and verbalize their experiences can help to support patients' ability to care for their body and to begin to integrate new experiences in their biographical identity. Therefore, health professionals should be educated in mindful communication and in the knowledge of different emotional aspects being affected after a TSCI. The aim of this education is to improve health professionals' ability to ask patients about their body experience, and to accompany the adjustment process early during rehabilitation, and therefore to individualize the rehabilitation process.

\section{Strengths and limitations}

For this qualitative interview-based pilot study, we recruited a sample from one rehabilitation center. Thus, it is uncertain how generalizable these results are to other populations with post-acute TSCI. We are aware that we missed important information by excluding participants with impaired cognitive or communication functioning, individuals who were not considered to be stable from a psychological perspective, as well as people after nontraumatic SCI. Nevertheless, this purposeful sample includes different lesion levels, ages, cultures, languages, and both genders. To the best of our knowledge, this is the first study to explore body experience during SCI postacute rehabilitation.

\section{Data availability}

Original data, the coding tree, and the original quotes have been stored by the corresponding author and can be sent on demand.

Acknowledgements The authors would like to thank all the participants of the study for their collaboration and their openness to sharing their personal experiences. We are grateful for various discussions with the team of psychologists. We thank Elias Torchalla for English editing the final paper.

Funding The Swiss Paraplegic Foundation, Nottwil, Switzerland, supported this study.

\section{Compliance with ethical standards}

Conflict of interest The authors report no conflict of interest with any organization regarding the material investigated and discussed in this research. This research was implemented during an internship at the Swiss Paraplegic Center and as a master's thesis for the University of Fribourg.

Publisher's note Springer Nature remains neutral with regard to jurisdictional claims in published maps and institutional affiliations.

\section{Appendix}

Consolidated criteria for reporting qualitative studies (COREQ): 32-item checklist

Domain 1: Research team and reflexivity

Personal Characteristics

1. Interviewer/facilitator: Which author/s conducted the interview or focus group?

See methods line 101-105.

2. Credentials: What were the researcher's credentials? E.g. $\mathrm{PhD}, \mathrm{MD}$

We added, that the study was part of the interviewer's (KB) master thesis. KB finished her MSc successful, AS is a $M D$. VC, HJ, KL and PL are PhD.

3. Occupation: What was their occupation at the time of the study?

We added that the interview was part of the interviewer's master thesis in the context of an internship in the area of psychological counselling in the rehabilitation clinic.

4. Gender: Was the researcher male or female?

$A S, V C, H J, K L$ and $K B$ are female, $P L$ is male.

5. Experience and training: What experience or training did the researcher have?

See methods. The other authors published several publication based on qualitative research.

Relationship with participants

6. Relationship established: Was a relationship established prior to study commencement?

See methods: The interviewer (KB) had no therapeutic relation with the participants.

7. Participant knowledge of the interviewer: What did the participants know about the researcher? e.g. personal goals, reasons for doing the research

See methods We added, that the study was part of the interviewers (KB) master thesis, now line 106. they were informed, that the interviews were conducted as part of the interviewer's master thesis in the context of an internship in the area of psychological counselling in the rehabilitation center.

8. Interviewer characteristics: What characteristics were reported about the interviewer /facilitator? e.g. Bias, assumptions, reasons and interests in the research topic

See methods: We added that the interview was part of the interviewer's master thesis in the context of an internship in the area of psychological counselling in the rehabilitation clinic.

\section{Domain 2: study design}

Theoretical framework

9. Methodological orientation and Theory: What methodological orientation was stated to underpin the study? e.g. grounded theory, discourse analysis, ethnography, phenomenology, content analysis 
See methods, data analyses line 129-143.

\section{Participant selection}

10. Sampling: How were participants selected? e.g. purposive, convenience, consecutive, snowball

See methods, sampling and recruitment: line 109-113

11. Method of approach: How were participants approached? e.g. face-to-face, telephone, mail, email

See methods, added face-to face contact, sampling and recruitment.

12. Sample size: How many participants were in the study?

See methods: sampling and recruitment.

13. Non-participation: How many people refused to participate or dropped out? Reasons?

See methods: no contacted patient refused.

Setting

14. Setting of data collection: Where was the data collected? e.g. home, clinic, workplace

See methods, sampling and recruitment: line 88-106.

15. Presence of non-participants: Was anyone else present besides the participants and researchers?

See methods: No, the interview was conducted only by $K B$ and audiotaped.

16. Description of sample: What are the important characteristics of the sample? e.g. demographic data, date

See methods, inclusion criteria and results table 2 .

Data collection

17. Interview guide: Were questions, prompts, guides provided by the authors? Yes, see table 1 (interview guide) p.4 Was it pilot tested?

See methods: yes five times.

18. Repeat interviews: Were repeat interviews carried out? If yes, how many?

Interviews were carried out once, see methods.

19. Audio /visual recording: Did the research use audio or visual recording to collect the data? See methods.

20. Field notes: Were field notes made during and /or after the interview or focus group?

See methods; No notes were taken and interviews audiotaped.

21. Duration: What was the duration of the interviews or focus group?

See results, line 148-149.

22. Data saturation: Was data saturation discussed?

Yes, see methods and limitation.

23. Transcripts returned: Were transcripts returned to participants for comment and /or correction?

See methods, data analyses. Participants did not check the transcribed interviews.

\section{Domain 3: analysis and findings}

Data analysis

24. Number of data coders: How many data coders coded the data?
See method data analyses.

25. Description of the coding tree: Did authors provide a description of the coding tree?

The coding tree and the original quotes are stored at the corresponding author and can be send on demand, see data archiving.

26. Derivation of themes: Were themes identified in advance or derived from the data?

See results. Themes were generated on the quotes taking the theoretical background in mind.

27. Software: What software, if applicable, was used to manage the data?

See methods, data analyses, MAXQDA $12^{\odot}$ (VERBI

Gmbh, version 2018)

28. Participant checking: Did participants provide feedback on the findings?

See methods, data analyses: No.

Reporting

29. Quotations presented: Were participant quotations presented to illustrate the themes/findings?

See tables 3-8, Yes; Was each quotation identified? e.g. participant number Yes.

30. Data and findings consistent: Was there consistency between the data presented and the findings?

See results, first paragraph.

31. Clarity of major themes: Were major themes clearly presented in the findings?

See results.

32. Clarity of minor themes: Is there a description of diverse cases or discussion of minor themes?

Minor findings are integrated in the different major findings in the result section.

\section{References}

1. Chhabra H. ISCOS textbook on comprehensive management of spinal cord injuries. India: Wolters Kluwer; pp. 978-93.

2. Sturm E. Rehabilitation von Querschnittgelähmten: Eine medizinischpsycholog. Studie: Huber; 1979.

3. World Health Organization, ISCOS. International perspectives on spinal cord injury. Geneve, Switzerland: World Health Organization; 2013.

4. Aldridge D. Music therapy and neurological rehabilitation: performing health. London, UK: Jessica Kingsley Publishers; 2005.

5. Lude P, editor. Querschnittlähmung: Psychologischer Forschungsstand. Psychotherapie Forum, Berlin, Germany: Springer; 2010.

6. Kennedy P, Lude P, Elfström M, Smithson E. Cognitive appraisals, coping and quality of life outcomes: a multi-centre study of spinal cord injury rehabilitation. Spinal Cord. 2010;48:762.

7. Lude P. Querschnittlähmung-Schritte der Bewältigung: Die Kraft der Psyche. Switzerland: Springer; 2016.

8. Kraft R, Dorstyn D. Psychosocial correlates of depression following spinal injury: a systematic review. J Spinal Cord Med. 2015;38:571-83.

9. Scheel-Sailer A, Post MW, Michel F, Weidmann-Hügle T, Baumann Hölzle R. Patients' views on their decision making during inpatient 
rehabilitation after newly acquired spinal cord injury-a qualitative interview-based study. Health Expect. 2017;20:1133-42.

10. Trautmann-Voigt S. Grammatik der Körpersprache: ein integratives Lehr-und Arbeitsbuch zum Embodiment; mit 18 Tabellen. Freiburg, Germany: Schattauer Verlag; 2012.

11. Hüther G, Storch M, Cantieni B, Tschacher W. Embodiment-Die Wechselwirkung von Körper und Psyche verstehen und nutzen, 2. Bern: Aufl Huber; 2010.

12. Joraschky P, Loew T, Röhricht F. Körpererleben und Körperbild: Ein Handbuch zur Diagnostik Stuttgart. Freiburg, Germany: Schattauer; 2009.

13. Tong A, Sainsbury P, Craig J. Consolidated criteria for reporting qualitative research (COREQ): a 32-item checklist for interviews and focus groups. Int J Qual Health Care. 2007;19:349-57.

14. Avalos L, Tylka TL, Wood-Barcalow N. The body appreciation scale: development and psychometric evaluation. Body Image. 2005;2:285-97.

15. Cash TF. Multidimensional body-self relations questionnaire (MBSRQ). Singapore: Encyclopedia of feeding and eating disorders, Springer; 2000; pp. 1-4.

16. Menzel JE. The psychometric validation of the physical body experiences questionnaire. Bull Menninger Clin. 2019;83: 53-83.

17. Daubenmier JJ. The relationship of yoga, body awareness, and body responsiveness to self-objectification and disordered eating. Psychol Women Q. 2005;29:207-19.

18. Rosenberg M. Rosenberg self-esteem scale (RSE). Accept Commit Ther Meas Package. 1965;61:18.

19. Kabat-Zinn J. Full catastrophe living, revised edition: how to cope with stress, pain and illness using mindfulness meditation. London, England: Hachette UK; 2013.

20. Dresing T, Pehl T. Praxisbuch interview, transkription $\&$ analyse. Anleitungen und Regelsysteme für qualitativ Forschende. 5. Auflage. Marburg. 2013.

21. Mayring P. Qualitative inhaltsanalyse. Weinheim, Germany: Beltz; 2015.

22. Van de Velde D, Bracke P, Van Hove G, Josephsson S, Devisch I, Vanderstraeten G. The illusion and the paradox of being autonomous, experiences from persons with spinal cord injury in their transition period from hospital to home. Disabil Rehabil. 2012;34:491-502.

23. Nevedal A, Kratz AL, Tate DG. Women's experiences of living with neurogenic bladder and bowel after spinal cord injury: life controlled by bladder and bowel. Disabil Rehabil. 2016;38: 573-81.

24. Kennedy P, Lude P, Elfström ML, Smithson EF. Psychological contributions to functional independence: a longitudinal investigation of spinal cord injury rehabilitation. Arch Phys Med Rehabil. 2011;92:597-602.

25. Migliorini CE, New PW, Tonge BJ. Comparison of depression, anxiety and stress in persons with traumatic and non-traumatic post-acute spinal cord injury. Spinal Cord. 2009;47:783-8.

26. Bailey KA, Gammage KL, van Ingen C, Ditor DS. Managing the stigma: exploring body image experiences and self-presentation among people with spinal cord injury. Health Psychol Open. 2016;3:2055102916650094.

27. Taleporos G, McCabe MP. Body image and physical disabilitypersonal perspectives. Soc Sci Med. 2002;54:971-80.
28. Finset A. Patient participation, engagement and activation: increased emphasis on the role of patients in healthcare. Patient Educ Couns. 2017;100:1245-6.

29. Gelis A, Stefan A, Colin D, Albert T, Gault D, Goossens D, et al. Therapeutic education in persons with spinal cord injury: a review of the literature. Ann Phys Rehabil Med. 2011;54:189-210.

30. van Leeuwen CM, Post MW, van Asbeck FW, Bongers-Janssen HM, van der Woude LH, de Groot S. et al. Life satisfaction in people with spinal cord injury during the first five years after discharge from inpatient rehabilitation. Disabil Rehabil. 2011;34:76-83.

31. Duff J, Kennedy P. Spinal cord injury. Handbook of clinical health psychology. West Sussex, England: Wiley; 2003. pp. 251-75.

32. Krause JS, Edles PA. Injury perceptions, hope for recovery, and psychological status after spinal cord injury. Rehabil Psychol. 2014;59:176.

33. Kennedy P, Evans M, Sandhu N. Psychological adjustment to spinal cord injury: the contribution of coping, hope and cognitive appraisals. Psychol Health Med. 2009;14:17-33.

34. Nierenberg B, Mayersohn G, Serpa S, Holovatyk A, Smith E, Cooper S. Application of well-being therapy to people with disability and chronic illness. Rehabil Psychol. 2016;61:32.

35. Lesky J. Bedürfnisse von Querschnittgelähmten im Rahmen der psychologischen Betreuung zur Zeit der Erstrehabilitation-Eine retrospektive Befragung. Die Rehabil. 2001;40:76-86.

36. van Diemen T, van Leeuwen C, van Nes I, Geertzen J, Post M. Body image in patients with spinal cord injury during inpatient rehabilitation. Arch Phys Med Rehabil. 2017;98:1126-31.

37. Eaton R, Jones K, Duff J. Cognitive appraisals and emotional status following a spinal cord injury in post-acute rehabilitation. Spinal Cord. 2018;56:1151-7.

38. Bonanno GA, Kennedy P, Galatzer-Levy IR, Lude P, Elfström ML. Trajectories of resilience, depression, and anxiety following spinal cord injury. Rehabil Psychol. 2012;57:236.

39. Kaiser S, Kennedy P. An exploration of cognitive appraisals following spinal cord injury. Psychol Health Med. 2011;16:708-18.

40. Middleton J, Craig A. Psychological challenges in treating persons with spinal cord injury. Psychological dynamics associated with spinal cord injury rehabilitation: new directions and best evidence. 2008:3-54.

41. Zanini C, Rubinelli S, Lustenberger N, Koch HG, Scheel-Sailer A, Brach $\mathrm{M}$. Challenges to building and maintaining partnership in the prevention and treatment of pressure injuries in spinal cord injury: a qualitative study of health professionals' views. Swiss Med Wkly. 2019;149:w20086

42. Essig S, Steiner C, Kühne T, Kremens B, Langewitz W, Kiss A. Communication skills training for professionals working with adolescent patients with cancer based on participants' needs: a pilot. J Adolesc Young Adult Oncol. 2019;8:354-62.

43. Langewitz W. Physician-patient communication in medical education: can it be learned? Bundesgesundheitsblatt Gesundheitsforschung Gesundheitsschutz. 2012;55:1176-82.

44. Roth K, Mueller G, Wyss A. Experiences of peer counselling during inpatient rehabilitation of patients with spinal cord injuries. Spinal Cord Ser Cases. 2019;5:1.

45. Skeels SE, Pernigotti D, Houlihan BV, Belliveau T, Brody M, Zazula J, et al. In: Craig A, Tran Y (eds) Psychological Aspects Associated Spinal Cord Injury Rehabilitation: New Directions and BEst Evidence. New York: Nova Science Publishers; 2008. 